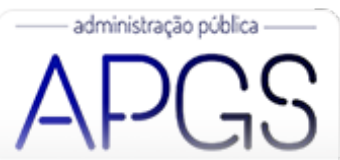

Administração Pública e Gestão Social ISSN: 2175-5787

apgs@ufv.br

Universidade Federal de Viçosa

Brasil

\title{
Regimes Próprios de Previdência Social: Uma Análise à Luz do Isomorfismo Institucional
}

\author{
Chaves da Silva, Anderson; Morais dos Santos, Odilanei \\ Regimes Próprios de Previdência Social: Uma Análise à Luz do Isomorfismo Institucional \\ Administração Pública e Gestão Social, vol. 12, núm. 4, 2020 \\ Universidade Federal de Viçosa, Brasil \\ Disponible en: http://www.redalyc.org/articulo.oa?id=351564289011
}

Esta obra está bajo una Licencia Creative Commons Atribución-NoComercial-SinDerivar 3.0 Internacional. 


\title{
Regimes Próprios de Previdência Social: Uma Análise à Luz do Isomorfismo Institucional
}

\author{
Special Social Welfare Policies of The Brazilian States: An Analysis in The Light of Institutional Isomorphism \\ Regímenes Propios de Previsión Social de Los Estados Brasileños: Un Análisis a la Luz del Isomorfismo Institucional
}

Anderson Chaves da Silva

Universidade Federal do Rio de Janeiro, Brasil

Redalyc: http://www.redalyc.org/articulo.oa?

anderson.azelha@gmail.com

Odilanei Morais dos Santos

Universidade Federal do Rio de Janeiro, Brasil

profodilanei@gmail.com

$\mathrm{id}=351564289011$

Recepción: 18 Mayo 2019

Aprobación: 26 Agosto 2019

Publicación: 01 Octubre 2020

\section{Resumo:}

De modo geral, pesquisas em previdência social tentam explicar o déficit financeiro dos regimes previdenciários por meio de argumentos relacionados às regras de elegibilidade e às mudanças na demografia nacional. Em uma tentativa não ortodoxa de apresentar uma possível explicação para parte desses déficits, este artigo pretende verificar a existência de práticas de isomorfismo entre as leis dos estados brasileiros e do Distrito Federal por ocasião da instituição de seus respectivos regimes próprios de previdência. Para atingir esse objetivo, preliminarmente, empregou-se a técnica de análise de conteúdo e, em seguida, a técnica econométrica de análise de correspondência, visando medir o grau de associação entre as variáveis definidas neste estudo. Os resultados estatísticos apontaram evidências de práticas de isomorfismo na maioria dos estados brasileiros, o que pode contribuir para explicar parte da ocorrência de déficits previdenciários estaduais em um mesmo período.

Palavras-Chave: Isomorfismo, Previdência, Análise de Conteúdo, Análise de Correspondência.

\section{Abstract:}

Overall, social security research attempts to explain the financial deficit of pension systems through arguments related to eligibility rules and changes in national demographics. In an unorthodox attempt to provide a possible explanation for some of these deficits, this article aims to verify the existence of isomorphism practices between the laws of the Brazilian states and the Federal District when their respective social security regimes were instituted. In order to reach this objective, the content analysis technique was firstly used, followed by the correspondence analysis econometric technique, aiming to measure the degree of association between the variables defined in this study. The statistical results showed evidence of isomorphism practices in most Brazilian states when defining their social security rules, which may contribute to explain part of the occurrence of state social security deficits in the same period.

KEYWORDS: Isomorphism, Social security, Content analysis, Correspondence Analysis.

\section{ReSUMEN:}

En general, la investigación de la seguridad social intenta explicar el déficit financiero de los sistemas de pensiones a través de argumentos relacionados con las reglas de elegibilidad y los cambios en la demografía nacional. En un intento poco ortodoxo de proporcionar una posible explicación para algunos de estos déficits, este artículo tiene como objetivo verificar la existencia de prácticas de isomorfismo entre las leyes de los estados brasileños y el Distrito Federal cuando se instituyeron sus respectivos regímenes de seguridad social. Para alcanzar este objetivo, primero se utilizó la técnica de análisis de contenido, seguida de la técnica econométrica de análisis de correspondencia, con el objetivo de medir el grado de asociación entre las variables definidas en este estudio. Los resultados estadísticos mostraron evidencia de prácticas de isomorfismo en la mayoría de los estados brasileños al definir sus reglas de seguridad social, lo que puede contribuir a explicar parte de la ocurrencia de déficits estatales de seguridad social en el mismo período.

Palabras Clave: Isomorfismo, Seguridad, Análisis de contenido, Análisis de Correspondencia. 


\section{INTRODUÇÃO}

A crise fiscal brasileira, iniciada em meados de 2014, ainda parece estar longe de ser resolvida e um dos pontos cruciais para amenizar essa situação é a aprovação de uma ampla reforma previdenciária (World Bank, 2017). Alinhado com esse posicionamento do Banco Mundial, no final de 2016, o poder executivo federal encaminhou ao Congresso Nacional a Proposta de Emenda à Constituição (PEC) 287/2016, visando promover tal reforma. No entanto, a tramitação da referida PEC foi suspensa, em função da intervenção federal no estado do Rio de Janeiro, instaurada pelo Decreto n. 9.288, de 16 de fevereiro de 2018, visando pôr termo ao comprometimento da ordem pública. De acordo com o $\$ 1^{\circ}$, art. 60 da Constituição Federal, a Carta Magna não pode ser emendada na vigência de intervenção federal.

Após a conclusão da sucessão presidencial de 2018, o debate sobre a previdência social retornou ao foco. Em 20 de fevereiro de 2019, o Presidente da República foi ao Congresso Nacional entregar uma nova PEC da reforma previdenciária. A PEC 6/2019 pretende modificar o sistema de previdência social, estabelecendo novos parâmetros para os benefícios do Regime Geral de Previdência Social (RGPS) e do Regime Próprio de Previdência Social (RPPS).

Especificamente com relação ao RPPS, que atende aos servidores públicos de todas as esferas de governo, de acordo com as respectivas legislações, a referida PEC visa a promover a convergência com as regras do RGPS, conforme consta na Exposição de Motivos apensada (Ministério da Economia [ME], 2019), mantendo-se, então, em consonância ao movimento de homogeneização iniciado pelas Emendas Constitucionais 20/1998 e $41 / 2003$.

Não obstante esse movimento de padronização, que integra o projeto do governo federal e visa, inclusive, a equacionar a situação financeira e atuarial do sistema previdenciário nacional no longo prazo (ME, 2019), os resultados apresentados pelos regimes próprios estaduais também são preocupantes, como se pode verificar nos números oficiais divulgados pela Secretaria do Tesouro Nacional (STN). Somente entre os anos de 2015 e 2017, o déficit previdenciário estadual consolidado aumentou 26,87\%, passando de, aproximadamente, $\mathrm{R} \$ 74,08$ bilhões para $\mathrm{R} \$ 93,99$ bilhões (STN, 2018). Cabe salientar que, apesar das anteriores reformas no sistema previdenciário brasileiro, as medidas implementadas per si não foram suficientes para impedir a trajetória de déficit observada (Braun, 2014).

Adicionalmente, considerando os dados de 2017 (ano mais recente do levantamento) apresentados no Boletim de Finanças dos Entes Subnacionais de 2018 da STN, o fato de se tratar de vinte e seis administrações estaduais e uma distrital parece não ter contribuído para resultados previdenciários distintos. Em maior ou menor grau, todos os entes da federação apresentaram resultado previdenciário deficitário.

É sabido que o Estado exerce forte influência institucional no que se refere aos sistemas previdenciários (Tafner, 2007). Tal influência pode vir a gerar uma homogeneidade na legislação previdenciária dos entes subnacionais. Com fundamento na teoria institucional, que procura explicar a estrutura e o funcionamento das organizações como uma realidade socialmente construída, esse procedimento é conhecido como isomorfismo (DiMaggio \& Powell, 1983). Entretanto, o fato de o Estado exercer influência sobre os entes subnacionais não prejudica a competência legislativa concorrente que lhes foi atribuída pela Constituição Federal de 1988. Logo, mesmo observando as regras gerais ditadas na Lei Federal 9.717/1998, também é possível que a legislação estadual possua, além de espécies legislativas distintas, dispositivos diferenciados entre os estados brasileiros, com atenção mais voltada para um ou outro aspecto.

Nesse sentido, o presente estudo exploratório pretende analisar a legislação previdenciária estadual que instituiu o regime próprio de previdência no Estado, com vistas a identificar a adoção pelos estados brasileiros e pelo Distrito Federal de práticas de isomorfismo, que podem contribuir para o entendimento de parte dos resultados previdenciários deficitários evidenciados pelos entes da federação. Como ressaltam DiMaggio e Powell (1983), a adoção de procedimentos isomórficos torna as instituições mais semelhantes e confere legitimidade a suas ações, sem necessariamente torná-las mais eficientes. Assim, a questão de pesquisa que se 
coloca é: Quais são as evidências de isomorfismo entre as leis dos estados brasileiros e do Distrito Federal por ocasião da instituição de seus respectivos regimes próprios de previdência?

A literatura nacional referente à previdência social é bastante ampla e diversificada. São vários os temas abordados nas pesquisas realizadas nessa área. Entretanto, com relação ao tema isomorfismo institucional, são poucos os estudos desenvolvidos. Pimentel, Chalegre e Porto (2015) analisaram as reformas previdenciárias promovidas na América Latina considerando que elas se deram a partir de um processo de isomorfismo institucional pautado na privatização total ou parcial dos seus sistemas. Lima, Oliveira, Ponte e Rebouças (2015), por sua vez, analisaram as práticas de governança corporativa adotadas e divulgadas pelos fundos de pensão brasileiros, sendo constatado que, segundo a Teoria Institucional, tais práticas decorrem de pressões coercitivas e culturais explicadas pelo isomorfismo.

Quanto ao déficit previdenciário, Santos et al. (2017) apresentaram duas causas fundamentais e complementares para o crescimento observado entre 2009 e 2015: O descompasso entre o rápido incremento do número de servidores inativos e a relativa estagnação dos servidores ativos, além da concessão, em vários estados da federação, de elevados aumentos reais de salário para os servidores ativos que foram, por força de lei, repassados aos inativos. Tafner (2007), por sua vez, relaciona essa questão com uma série de fatores relacionados às regras de elegibilidade dos benefícios, bem como ao cálculo de seu valor.

Desta maneira, vislumbra-se uma lacuna na literatura referente à análise da legislação previdenciária estadual à luz da teoria do isomorfismo institucional, que pode contribuir para o debate acerca do déficit previdenciário evidenciado pelos estados brasileiros, o que torna este estudo relevante não apenas para a comunidade acadêmica, mas também para os profissionais que atuam na área.

Por intermédio de uma avaliação qualitativa, com fundamento na análise de conteúdo, e quantitativa, ancorada na técnica de Análise de Correspondência (ANACOR), o presente estudo exploratório busca contribuir com a literatura sobre o sistema previdenciário nacional, demonstrando a maneira como as leis estaduais estão correlacionadas entre si. Para tanto, o estudo se inicia com esta breve introdução, seguida de um referencial teórico sobre os regimes próprios de previdência e a teoria institucional. Na seção posterior, a metodologia da análise é descrita e os resultados decorrentes são abordados em seguida. Por fim, as considerações finais são apresentadas.

\section{REFERENCIAL TEÓRICO}

\section{Regimes Próprios de Previdência Social}

Os sistemas previdenciários decorrem dos processos de proletarização e de urbanização, uma vez que expõem os trabalhadores e suas famílias a riscos de miserabilidade sem qualquer rede de proteção social (Tafner, 2007). Segundo Ibrahim (2011), a proteção social brasileira seguiu os mesmos passos do plano internacional, surgindo na iniciativa privada, de maneira voluntária e com uma crescente intervenção do Estado. O montepio para a guarda pessoal de D. João VI é um exemplo dos mais antigos sistemas de proteção social.

Ao longo dos anos, esse sistema foi sendo aprimorado e desenvolvido até chegar à forma atual contida na Constituição Federal de 1988 (CF/88). São basicamente dois regimes: O Regime Geral de Previdência Social (RGPS), destinado aos trabalhadores da iniciativa privada, e o Regime Próprio de Previdência Social (RPPS), que atende os servidores públicos. Adicionalmente, há o Regime Complementar de Previdência, sendo este de natureza facultativa (Brasil, 1988).

Os RPPS são mantidos pelas unidades da federação em favor de seus servidores públicos. Em regra, esses servidores não são amparados pelo RGPS, de responsabilidade, apenas, da União (Ibrahim, 2011). Assim, apesar de o assunto seguridade social, que engloba previdência, assistência e saúde, ser de competência privativa da União, conforme inciso XXIII, do art. 22, da CF/88, a própria Constituição estabelece que 
a previdência social é objeto de competência legislativa concorrente entre os entes da federação, conforme inciso XII, do art. 24, da CF/88.

Considerando essa capacidade legislativa, por intermédio da Carta Magna, a União estabeleceu as regras gerais do sistema previdenciário dos servidores em seu art. 40 . Merece destaque o contido no $\$ 4^{\circ}$, que veda "a adoção de requisitos e critérios diferenciados para a concessão de aposentadoria aos abrangidos pelo regime de que trata este artigo", ressalvados os casos definidos em leis complementares (Constituição da República Federativa do Brasil, 1988).

A organização dos RPPS deve observar os dispositivos da Lei n. 9.717, de 27 de novembro de 1998, que versam sobre regras gerais e o funcionamento dos RPPS da União, dos estados, do Distrito Federal e dos municípios. Um aspecto relevante é o estabelecimento de diretrizes que visam a garantir o equilíbrio financeiro e atuarial do regime de previdência (Lei n. 9.717, 1998). Por sinal, este tem sido o grande desafio dos entes federativos: Combater o desequilíbrio, ou seja, o déficit previdenciário.

Tafner (2007) destaca que o desempenho e o equilíbrio de um sistema previdenciário estão relacionados com fatores endógenos, como a existência ou não de idade mínima para a aposentadoria, a forma de cálculo do benefício, a taxa de reposição previdenciária, as regras relativas ao benefício de pensão, as regras sobre a aposentadoria por invalidez, entre outros.

Há que se ressaltar, entretanto, que todas as reformas promovidas desde 1988 não foram suficientes para a manutenção do equilíbrio financeiro e atuarial (Braun, 2014). A dificuldade de inverter essa tendência pode residir em outros aspectos, relacionados à operacionalidade do RPPS, que também afetam o resultado, como corrupção e fraudes na gestão dos recursos previdenciários (Braun, 2014).

À época da apresentação da PEC 287/2016, o Banco Mundial afirmou que a proposta do governo federal buscava alinhar as práticas previdenciárias nacionais ao padrão internacional, contribuindo para que o sistema fosse mais sustentável (World Bank, 2017). A PEC 6/2019, por sua vez, pretende reduzir o endividamento primário, combatendo a dívida pública pela redução de seu custo e buscando equidade entre os beneficiários, convergência entre os regimes, separação entre previdência e assistência, e sustentabilidade da nova previdência pública (ME, 2019).

A Tabela 1 apresenta a evolução da trajetória deficitária no âmbito dos RPPS dos estados brasileiros entre os anos de 2015 e 2017 (Secretaria do Tesouro Nacional [STN], 2018). Tais dados reafirmam o entendimento de Braun (2014) de que há um problema de insustentabilidade dos regimes previdenciários estaduais não solucionado pelas reformas pretéritas, que enseja o emprego de recursos financeiros não vinculados à previdência. 
Tabela 1 - Déficit Previdenciário Estadual (em milhões de reais)

\begin{tabular}{llll}
\hline UF & 2015 & 2016 & 2017 \\
\hline AC & 237 & 288 & 409 \\
AL & 1.238 & 1.140 & 1.285 \\
AM & 989 & 999 & 1.154 \\
AP & 13 & 34 & 14 \\
BA & 2.341 & 2.537 & 3.224 \\
CE & 1.369 & 1.449 & 1.576 \\
DF & 1.329 & 1.212 & 564 \\
ES & 1.603 & 1.802 & 1.994 \\
GO & 1.995 & 2.220 & 2.613 \\
MA & 687 & 763 & 1.137 \\
MG & 11.927 & 13.402 & 15.322 \\
MS & 1.151 & 1.136 & 1.658 \\
MT & 694 & 1.105 & 1.396 \\
PA & 2.078 & 2.228 & 1.424 \\
PB & 1.029 & 1.135 & 1.303 \\
PE & 1.823 & 2.132 & 2.563 \\
PI & 557 & 573 & 457 \\
PR & 2.375 & 2.299 & 4.450 \\
RJ & 8.679 & 10.821 & 13.063 \\
RN & 1.257 & 1.398 & 1.502 \\
RO & 9 & 8 & 8 \\
RR & 3 & 27 & 5 \\
RS & 8.703 & 9.749 & 10.699 \\
SC & 3.247 & 3.070 & 3.665 \\
SE & 871 & 897 & 946 \\
SP & 17.877 & 19.797 & 21.340 \\
TO & 0 & 0 & 214 \\
\hline TOTAL & 74.079 & 82.221 & 93.986 \\
\hline & & &
\end{tabular}

Fonte: Adaptado de STN (2018).

Os dados da Tabela 1 evidenciam que o regime previdenciário de todos os estados brasileiros, no ano de 2017, apresentou resultado deficitário. É possível identificar, ainda, que o déficit previdenciário estadual consolidado aumentou 26,87\% entre 2015 e 2017. Mesmo estados como Rondônia, Roraima e Tocantins que, historicamente, possuíam uma previdência superavitária, conforme STN (2018), apresentaram resultados negativos.

É possível verificar, ainda, que o déficit previdenciário retraiu em três estados (Pará, Piauí e Rondônia) e no Distrito Federal, onde a redução foi de R $\$ 765$ milhões, o que representa 57,6\%. Entretanto, em todos os demais estados, o resultado negativo seguiu a trajetória de crescimento, entre 2015 e 2017, alcançando percentuais superiores a 50\% em estados como Rio de Janeiro (50,5\%), Maranhão (65,5\%), Roraima (66,7\%), Acre (72,6\%), Paraná (87,4\%) e Mato Grosso (101,2\%). Merece atenção o resultado de Tocantins que, em 2015 , não apresentava déficit e, em 2017, passou a ser deficitário em R $\$ 214$ milhões.

Questões relacionadas ao aumento de servidores inativos e concessão de aumentos salariais reais, tanto para ativos quanto para inativos, podem explicar a evolução desses déficits previdenciários (Santos et al., 2017).

Considerando que há uma forte influência institucional do Estado nos sistemas previdenciários, é importante que haja uma adequada gestão dos recursos previdenciários, os quais são empregados como instrumento de transferência de renda à sociedade, com fundamento no sistema eleitoral (Tafner, 2007).

\section{Isomorfismo Institucional}

O isomorfismo, no âmbito da teoria institucional, é visto como o conceito que demonstra com maior nitidez o processo de homogeneização organizacional, que constrange e força uma unidade em uma população ou 
em um campo organizacional a assemelhar-se com outras que estão expostas às mesmas condições ambientais (DiMaggio \& Powell, 1983).

Nesse sentido, o que se verifica é que mudanças estruturais nas organizações parecem cada vez menos impulsionadas pela concorrência ou necessidade de eficiência. A burocratização e outras formas de mudança derivam de processos que tornam as organizações mais semelhantes, sem necessariamente torná-las mais eficientes (DiMaggio \& Powell, 1983).

Nessa linha de raciocínio, Dias e Machado (2008) utilizam a implantação da Lei de Responsabilidade Fiscal como exemplo de que as instituições foram obrigadas a reforçar seus controles na área contábil, sem saber, no entanto, se tais controles produziriam os efeitos desejados. Ou seja, as instituições passam a utilizar determinados mecanismos de controle não porque acreditam que sejam eficazes, eficientes, mas porque são obrigadas a utilizá-los.

DiMaggio e Powell (1983) salientam que campos organizacionais bem estruturados fornecem um contexto em que os esforços individuais para lidar racionalmente com a incerteza e a restrição, muitas vezes, levam à homogeneidade na estrutura, na cultura e na produção. O conceito que melhor explica esse processo é o isomorfismo, que pode se configurar de três formas: Isomorfismo coercitivo, normativo ou mimético (DiMaggio \& Powell, 1983).

$\mathrm{O}$ isomorfismo coercitivo resulta de pressões formais e informais exercidas sobre as organizações e das expectativas culturais da sociedade em que atuam essas organizações. Essas pressões podem ser sentidas pelas organizações como coerção, persuasão ou como convite para se unirem. Em resumo, decorrem da influência política no campo organizacional (DiMaggio \& Powell, 1983).

$\mathrm{O}$ isomorfismo normativo, associado à profissionalização, possui dois aspectos que contribuem para esse processo: $\mathrm{O}$ apoio da educação e a legitimação em uma base cognitiva produzida por especialistas da universidade, e o crescimento e a elaboração de redes profissionais nas organizações em que novos modelos se difundem rapidamente. "Atores externos podem induzir uma organização a se conformar a seus pares ao exigir o desempenho de uma tarefa particular e especificar a profissão responsável por esse desempenho" (DiMaggio \& Powell, 1983, p. 150).

Por fim, o isomorfismo resultado de processos miméticos processa-se na adoção com a finalidade de reduzir a incerteza ocasionada por problemas tecnológicos, objetivos conflitantes e exigências institucionais (Machado-da-Silva \& Fonseca, 1993). O mimetismo pode resultar em inovação, até mesmo de forma inconsciente, com a aquisição involuntária de atributos adquiridos de uma organização "modelo" imitada (DiMaggio \& Powell, 1983).

Machado-da-Silva e Fonseca (1993) argumentam que a autodefesa diante de situações sem soluções aparentes justifica a adoção de posturas isomórficas em relação aos líderes do campo organizacional, considerando que a semelhança contribui para as transações interorganizacionais.

Para Meyer e Rowan (1977), as organizações são estruturadas por fenômenos em seus ambientes e tendem a se tornar isomórficas com eles. Segundo os autores, isto se deve ao fato de os elementos estruturais se difundirem porque os ambientes criam exigências limitadoras para as organizações. Assim, aquelas organizações que adotam práticas isomórficas acabam se tornando capazes de gerenciar as interdependências técnicas.

No contexto da previdência social, Pimentel, Chalerge e Porto (2015) evocam o institucionalismo sociológico para a análise das políticas públicas, com vistas a argumentar que as reformas nos sistemas de previdência ocorridas na América Latina se deram a partir de um processo de isomorfismo institucional gerado pela adoção de um mito racional que tornou as instituições similares sem, no entanto, torná-las mais eficientes, alinhando com o entendimento de DiMaggio e Powell (1983).

O desafio de analisar o isomorfismo institucional e seus impactos conduziu os autores a uma reflexão a respeito dos critérios metodologicamente adequados para a avaliação, uma vez que consideraram insuficiente avaliar o resultado das reformas em relação ao atingimento de seus objetivos. Logo, considerando que o 
isomorfismo ocorre independente de seus resultados em termos de eficiência, Pimentel, Chalerge e Porto (2015) decidiram avaliar o isomorfismo a partir da análise da alteração da estrutura das organizações previdenciárias, da adoção de critérios externos de avaliação e da estabilização em relação ao novo ambiente institucional em questão, evidenciando um rico caminho para pesquisas futuras.

Lima et al. (2015), por sua vez, empregaram o isomorfismo institucional para analisar as práticas de governança corporativa adotadas e divulgadas pelos fundos de pensão brasileiros. Os autores salientam que a adoção de elevados padrões de governança é necessária em face do amplo volume de recursos movimentado pelos fundos de pensão. A importância da boa governança nesses fundos reflete na melhoria do desempenho dos investimentos e na segurança de seu benefício.

O estudo identificou a predominância do isomorfismo coercitivo na divulgação e adoção de práticas de governança corporativa, decorrente da regulação dos fundos de pensão. Quando as práticas eram voluntárias, observou-se um elevado nível de heterogeneidade, não permitindo a caracterização do isomorfismo normativo. Além disso, o isomorfismo mimético esteve presente nas práticas voluntárias quando correlacionadas às variáveis correspondentes a idade e tamanho dos fundos de pensão. Assim, os autores concluíram que as práticas adotadas e divulgadas por esses fundos podem ser explicadas pelos isomorfismos coercitivo e mimético, ressaltando o papel exercido pelas instituições reguladoras (Lima, Oliveira, Ponte, \& Rebouças, 2015).

Cabe citar ainda o estudo de Paula, Faria, França e Tavares (2018), que aborda o isomorfismo institucional de forma transversal ao analisar a presença de elementos de accountability nas leis que estruturam os RPPS dos municípios do estado de Minas Gerais. A partir dos resultados desse estudo, que indicaram baixos níveis de accountability na legislação municipal, os autores sugerem a adoção de práticas de isomorfismo, por entenderem que isto possibilitaria uma melhor adequação da estrutura legal aos melhores mecanismos de governança e accountability.

De todo o exposto, acredita-se ser possível utilizá-los para analisar a legislação previdenciária dos regimes próprios estaduais com vistas a identificar a existência de práticas de isomorfismo.

\section{METODOLOGIA}

Visando responder à questão de pesquisa, desenvolveu-se a presente análise com o apoio da técnica de Análise de Conteúdo, empregada para identificar sinais em blocos de textos e convertê-los em valores numéricos (Campbell, 2017), de modo a viabilizar a realização de inferências replicáveis e válidas de dados de acordo com seu contexto (Krippendorff, 2004).

Inicialmente, seguindo os passos elencados por Bowen e Bowen (2008) para a realização de uma análise de conteúdo, efetuou-se o levantamento das leis que instituíram os respectivos RPPS nos estados e no Distrito Federal. Em regra, o acesso deu-se a partir de consulta aos sítios oficiais dos respectivos entes. Para alguns casos, a pesquisa foi realizada com o auxílio do sítio www.google.com, já que o sítio institucional não apresentava informações sobre o respectivo regime previdenciário. Como se pretende analisar a ocorrência de práticas de isomorfismo na legislação previdenciária, para tentar explicar parte dos déficits previdenciários observados, buscou-se pesquisar a legislação imediatamente após aquela em que a União estabeleceu as regras gerais para os RPPS. Ou seja, para o presente estudo, todas as atualizações ocorridas após a legislação inicial foram desconsideradas.

O Quadro 1 apresenta o ano em que os respectivos entes federativos instituíram seus RPPS. Esta informação é relevante pois contribui para identificar práticas de isomorfismo pelos estados que instituíram seus regimes previdenciários em momento posterior. 
Quadro 1 - Ano da Lei que instituiu o RPPS nos Estados Brasileiros

\begin{tabular}{|l|l|l|l|l|l|l|l|l|l|l|l|}
\hline 1998 & 1999 & 2000 & 2001 & 2002 & 2003 & 2004 & 2005 & 2007 & 2008 & 2009 & 2011 \\
\hline PR & AP & GO & AM & AL & PB & ES & AC & SP & DF & BA & RS \\
MA & CE & MS & TO & MG & & MT & RN & & RJ & & \\
& RR & $\begin{array}{l}\text { PE } \\
\text { RO }\end{array}$ & & PA & & PI & & & SC & & \\
\hline
\end{tabular}

Com relação aos dados apresentados no Quadro 1, há que se salientar que:

a) A Lei 12.398/1998, do Paraná, criou o Sistema de Seguridade Social. No Maranhão, a Lei 7.357/1998 também criou o referido sistema no estado, mas foi revogada pela Lei Complementar 73/2004. Em ambos estados não foi identificada uma lei específica que tenha instituído o RPPS estadual;

b) A Lei 1.246/2001, do Tocantins, reestruturou o RPPS, criado pela Lei 72/1989. No Rio Grande do Norte, a Lei Complementar 308/2005 também reestruturou o regime estadual, criado pela Lei 2.728/1962;

c) A Lei Complementar 282/2004, do Espírito Santo, reorganizou e unificou o RPPS, criado pela Lei Complementar 109/1997. No Distrito Federal, a Lei Complementar 769/2008 também reorganizou e unificou o regime distrital. A pesquisa não identificou as leis anteriores a essa Lei Complementar;

d) No Piauí, a Lei 4.051/1986 criou o RPPS estadual. Para adequar-se à legislação federal, o Estado sancionou três leis complementares: Lei Complementar 39/2004, que institui o Fundo de Previdência do RPPS estadual; Lei Complementar 40/2004, que dispóe sobre o plano de custeio do RPPS dos servidores civis; e Lei Complementar 41/2004, que disciplina o plano de custeio do RPPS dos militares e bombeiros militares do estado. Não foi identificada a existência de uma única legislação tratando o regime previdenciário como um todo;

e) Em São Paulo, o RPPS foi instituído pela Lei Complementar 180/1978. Com o advento da Lei Federal 9.717/1998, o estado sancionou diversas leis, dentre as quais a Lei Complementar 943/2003, que instituiu contribuição previdenciária para custeio do sistema; a Lei Complementar 954/2003, que instituiu contribuição previdenciária para inativos e pensionistas; a Lei Complementar 1.010/2007, que criou a Unidade Gestora do RPPS; a Lei Complementar 1.012/2007, que alterou dispositivos relativos à percepção do benefício de pensão por morte; e a Lei Complementar 1.013/2007, que alterou dispositivos referentes aos benefícios dos militares. De forma similar ao estado do Piauí, não foi identificada a existência de uma única legislação tratando do regime previdenciário estadual como um todo.

Tendo em vista tais observações, optou-se por excluir da presente análise as legislações dos estados do Paraná e do Maranhão, por não possuírem uma lei específica que aborde a instituição do respectivo RPPS, e os estados do Piauí e de São Paulo, por terem os dispositivos referentes ao RPPS estadual dispersos em várias leis. Dessa maneira, esta é uma limitação do presente estudo.

Uma vez definida a amostra, realizou-se uma análise documental na Lei Federal, objetivando definir quais variáveis qualitativas fariam parte do presente estudo. Em seus doze artigos, identificou-se um direcionamento para os estados brasileiros em três aspectos: Os segurados dos regimes próprios de previdência, os possíveis benefícios desses regimes e as formas de financiamento de tais benefícios. Assim, foram definidas três variáveis:

a) Segurados, com três categorias distintas: Servidor, militar e dependentes;

b) Benefícios, com seis categorias distintas: Aposentadoria, pensão, auxílio-doença, salário-maternidade, salário-família e auxílio-reclusão;

c) Financiamento, com três categorias distintas: Contribuição, fundo e compensação.

Em seguida, desenvolveu-se análise de conteúdo de todas as legislações, com o auxílio do software Maxqda , com vistas a identificar os elementos correspondentes às variáveis qualitativas e suas categorias. A análise 
de conteúdo trata os elementos textuais como entidades empíricas, o que permite a realização de tal procedimento (Bowen \& Bowen, 2008).

A quantidade total de registros, que são os elementos da legislação codificados a partir da pesquisa lexical utilizada no software, foi de 6.747 unidades. Tais unidades foram distribuídas nas categorias das variáveis predefinidas (segurados, benefícios e financiamento), levando em consideração seu valor semântico.

Os dados foram tratados no software IBM $^{\bullet}$ SPSS Statistics versão 22, para o cálculo do Qui-quadrado $\left(\chi^{2}\right.$.) dos resíduos padronizados e aplicação da Análise de Correspondência (ANACOR), que é uma técnica de interdependência exploratória que aborda a distribuição de frequências resultantes de duas variáveis qualitativas de cada vez, visando explicar a associação entre categorias dessas variáveis. Essa associação é evidenciada em um mapa perceptual, que permite um exame visual do padrão ou estrutura dos dados (Fávero, Belfiore, Silva, \& Chan, 2009).

\section{ANÁLISE E RESULTADOS}

É importante salientar que a Lei Federal n. 9.717, de 27 de novembro de 1998, dispõe sobre regras gerais para a organização e o funcionamento dos RPPS dos servidores públicos federais, estaduais, distritais e municipais, e dos militares estaduais e distritais (Brasil, 1998). Uma vez que seus dispositivos são de observância obrigatória, seria possível afirmar que a União exerce uma força institucional perante os entes subnacionais ao impor as diretrizes básicas à legislação do RPPS, o que pode contribuir para a homogeneização da legislação previdenciária, por meio do fenômeno conhecido como isomorfismo coercitivo.

No entanto, há que se salientar que o fato de tais regras gerais derivarem de uma legislação federal não prejudica a capacidade legislativa concorrente dos entes subnacionais definida na Constituição Federal. Se assim fosse, não haveria que se falar de isomorfismo na área pública, pois caberia aos entes subnacionais utilizar as leis federais, desconsiderando quaisquer especificidades dos estados. Todavia, não é isto que está previsto no texto constitucional, no federalismo estabelecido no país.

Os entes federados possuem discricionariedade para decidir, além da forma legislativa a ser adotada, que confere níveis distintos de segurança jurídica (uma lei complementar, por exemplo, é mais segura, do ponto de vista jurídico, do que uma portaria de uma secretaria de governo estadual), quais aspectos do regime próprio de previdência merecem mais ou menos atenção no âmbito de seus estados. Essa situação ficou caracterizada no estudo de Paula et al. (2018), que analisou a presença de elementos de accountability nas leis que estruturam os RPPS dos municípios do estado de Minas Gerais e identificou realidades diferentes nas respectivas legislações em todas as dimensões analisadas. Tal situação contribuiu, inclusive, para que os autores sugerissem a adoção de práticas de isomorfismo visando possibilitar uma melhoria da adequação da estrutura legal aos mecanismos de governança e accountability.

Assim, enfatizada a viabilidade de se analisar a adoção de práticas de isomorfismo na legislação previdenciária dos estados, a presente análise se deu a partir dos mapas perceptuais elaborados, sendo possível efetuar algumas inferências, considerando os dados constantes do Quadro 1, que evidenciam o ano das leis que instituíram os RPPS estaduais. Ressalta-se que os resultados alcançados não podem ser generalizados para observações não pertencentes à amostra aqui utilizada, conforme assevera Fávero, Belfiore, Silva e Chan (2009).

Os primeiros estados brasileiros a sancionarem leis sobre o RPPS estadual, adequando-se aos dispositivos da Lei Federal 9.717/1998, foram Amapá, Ceará e Roraima. Assim, a adoção de práticas de isomorfismo entre os estados brasileiros foi analisada tendo como referência as leis desses estados.

Preliminarmente, realizou-se o teste $\chi^{2}$, visando identificar a existência de associação entre as variáveis do estudo, conforme demonstrado na Tabela 2. 
Tabela 2 - Teste Qui-quadrado

\begin{tabular}{lll}
\hline Variáveis & $\chi^{2}$ & $p$-value \\
\hline $\begin{array}{l}\text { Lei estadual e } \\
\text { segurados }\end{array}$ & 212,571 & 0,000 \\
$\begin{array}{l}\text { Lei estadual e } \\
\text { benefícios }\end{array}$ & 403,188 & 0,000 \\
$\begin{array}{l}\text { Lei estadual e } \\
\text { financiamento }\end{array}$ & 337,424 & 0,000 \\
\hline
\end{tabular}

Os resultados permitem, ao nível de significância de 5\%, rejeitar a hipótese nula do teste $\left(\mathrm{H}_{0} .:\right.$ as variáveis são independentes), e dar continuidade à Análise de Correspondência.

\section{Segurados}

A análise da relação entre as leis estaduais e os segurados do RPPS se deu a partir de 2.399 observações. A Tabela de Correspondência (Tabela 3 ) apresenta a frequência das categorias da variável "segurados” em cada legislação estadual da amostra utilizada no presente estudo.

De sua análise, tem-se que as categorias "servidor" e "dependentes" foram as mais frequentes, $1.071 \mathrm{e}$ 1.068 observações respectivamente, o que nos permite identificar um foco maior, por parte dos legisladores estaduais, para tais categorias por ocasião da criação de seus respectivos RPPS. Ao se analisar a distribuição de frequências nas respectivas leis estaduais, identifica-se que a lei do estado de Minas Gerais foi a que mais possui registros na categoria "servidor" (89), seguida pelas leis dos estados de Alagoas (78) e Pernambuco (76). A categoria "dependentes", por sua vez, apresentou mais registros na lei do estado de Goiás (98), seguida pelas leis dos estados de Alagoas (83) e Pernambuco (72).

Adicionalmente, é possível verificar uma baixa frequência na categoria "militar", 260 ocorrências (cerca de $10,84 \%$ do total de observações), o que pode sugerir a existência de outros dispositivos normativos destinados a regulamentar os benefícios previdenciários dos seus militares. Nota-se que há ao menos cinco estados com menos de três registros nesta categoria em suas leis que instituíram o RPPS. 
Tabela 3 - Tabela de Correspondência (lei estadual e segurados)

\begin{tabular}{lllll}
\hline \multirow{2}{*}{$\begin{array}{l}\text { Lei } \\
\text { estadual }\end{array}$} & \multicolumn{4}{l}{ Segurados } \\
\cline { 2 - 5 } & Servidor Militar Dependentes ativa \\
\hline Lei TO & 32 & 14 & 36 & 82 \\
Lei GO & 55 & 22 & 98 & 175 \\
Lei MS & 40 & 13 & 31 & 84 \\
Lei MT & 10 & 4 & 5 & 19 \\
Lei DF & 75 & 1 & 58 & 134 \\
Lei RN & 59 & 23 & 57 & 139 \\
Lei SE & 54 & 35 & 55 & 144 \\
Lei PB & 22 & 8 & 11 & 41 \\
Lei PE & 76 & 21 & 72 & 169 \\
Lei AL & 78 & 24 & 83 & 185 \\
Lei BA & 73 & 10 & 55 & 138 \\
Lei CE & 14 & 11 & 27 & 52 \\
Lei RJ & 33 & 5 & 34 & 72 \\
Lei ES & 33 & 7 & 43 & 83 \\
Lei MG & 89 & 0 & 38 & 127 \\
Lei RS & 15 & 0 & 9 & 24 \\
Lei SC & 21 & 5 & 64 & 90 \\
Lei RO & 52 & 19 & 34 & 105 \\
Lei RR & 48 & 2 & 29 & 79 \\
Lei PA & 57 & 19 & 49 & 125 \\
Lei AC & 26 & 1 & 46 & 73 \\
Lei AM & 47 & 12 & 67 & 126 \\
Lei AP & 62 & 4 & 67 & 133 \\
\hline Margem & 1.071 & 260 & 1.068 & 2.399 \\
ativa & & & & \\
\hline
\end{tabular}

Os resultados da ANACOR evidenciaram que a técnica de interdependência explica 8,9\% da variância $(0,089)$, também conhecida como inércia total, em que a primeira dimensão corresponde a 58,1\% $(0,052)$ e a segunda dimensão 41,9\% (0,037) da inércia total. Segundo Fávero et al. (2009, p. 274), "as categorias mais explicativas das dimensões são as que apresentam maior inércia por dimensão e que simultaneamente se situam mais afastadas da origem $(0,0)$ ".

No que se refere à variável "lei estadual", a categoria dominante da primeira dimensão foi a lei do estado de Minas Gerais, que contribuiu com $25,1 \%$ da sua inércia, enquanto a lei do estado de Santa Catarina foi a categoria dominante da segunda dimensão, respondendo por $28,6 \%$ da sua inércia. Com relação à variável "segurados", a categoria dominante na primeira dimensão foi a "militar", que respondeu por $73,5 \%$ da inércia da dimensão, enquanto na segunda dimensão, a categoria dominante foi a "dependentes", responsável por $54,8 \%$ da inércia da dimensão.

Um ponto importante desta análise diz respeito aos resíduos padronizados, também conhecidos como medidas de similaridade (Fávero et al., 2009). Os resíduos representam as diferenças entre as frequências esperadas e as observadas. Quando os valores são negativos, há uma indicação de menor associação entre as variáveis. Considerando que o objetivo deste estudo é identificar práticas de isomorfismo na legislação estadual que criou os respectivos RPPS, os resíduos padronizados, ou seja, as medidas de similaridades fornecem um razoável indicativo de tais práticas. A Tabela 4 apresenta os resíduos padronizados para as variáveis "lei estadual" e "segurados". 
Tabela 4 - Resíduos Padronizados (lei estadual e segurados)

\begin{tabular}{llll}
\hline \multirow{2}{*}{ Lei_estadual } & \multicolumn{2}{l}{ Segurados } \\
\cline { 2 - 4 } & Servidor & Militar & Dependentes \\
\hline Lei TO & $-0,762$ & 1,715 & $-0,084$ \\
Lei GO & $-2,616$ & 0,697 & 2,276 \\
Lei MS & 0,408 & 1,291 & $-1,046$ \\
Lei MT & 0,521 & 1,352 & $-1,189$ \\
Lei DF & 1,962 & $-3,548$ & $-0,214$ \\
Lei RN & $-0,388$ & 2,045 & $-0,620$ \\
Lei SE & $-1,283$ & 4,909 & $-1,137$ \\
Lei PB & 0,864 & 1,687 & $-1,698$ \\
Lei PE & 0,064 & 0,627 & $-0,373$ \\
Lei AL & $-0,505$ & 0,882 & 0,071 \\
Lei BA & 1,451 & $-1,282$ & $-0,821$ \\
Lei CE & $-1,912$ & 2,260 & 0,800 \\
Lei RJ & 0,151 & $-1,004$ & 0,344 \\
Lei ES & $-0,666$ & $-0,665$ & 0,995 \\
Lei MG & 4,290 & $-3,710$ & $-2,465$ \\
Lei RS & 1,309 & $-1,613$ & $-0,515$ \\
Lei SC & $-3,026$ & $-1,522$ & 3,781 \\
Lei RO & 0,748 & 2,259 & $-1,864$ \\
Lei RR & 2,144 & $-2,243$ & $-1,040$ \\
Lei PA & 0,160 & 1,481 & $-0,891$ \\
Lei AC & $-1,154$ & $-2,457$ & 2,368 \\
Lei AM & $-1,233$ & $-0,448$ & 1,456 \\
Lei AP & 0,341 & $-2,743$ & 1,012 \\
\hline
\end{tabular}

A análise dos resíduos padronizados permite caracterizar as categorias da variável "segurados" com as leis estaduais, considerando os valores positivos das colunas da Tabela 4, da seguinte maneira:

a) Servidor - treze leis dos estados em ordem decrescente de importância: Minas Gerais, Roraima, Distrito Federal, Bahia, Rio Grande do Sul, Paraíba, Rondônia, Mato Grosso, Mato Grosso do Sul, Amapá, Pará, Rio de Janeiro e Pernambuco;

b) Militar - doze leis dos estados em ordem decrescente de importância: Sergipe, Ceará, Rondônia, Rio Grande do Norte, Tocantins, Paraíba, Pará, Mato Grosso, Mato Grosso do Sul, Alagoas, Goiás e Pernambuco;

c) Dependentes - nove leis dos estados em ordem decrescente de importância: Santa Catarina, Acre, Goiás, Amazonas, Amapá, Espírito Santo, Ceará, Rio de Janeiro e Alagoas.

É de se esperar que essas associações positivas estejam próximas no mapa perceptual (Figura 1), uma vez que indicam a similaridade existente entre tais leis para cada uma das categorias da variável "segurados". Essa representação gráfica é uma forma simplificada e de fácil interpretação dos resultados. 


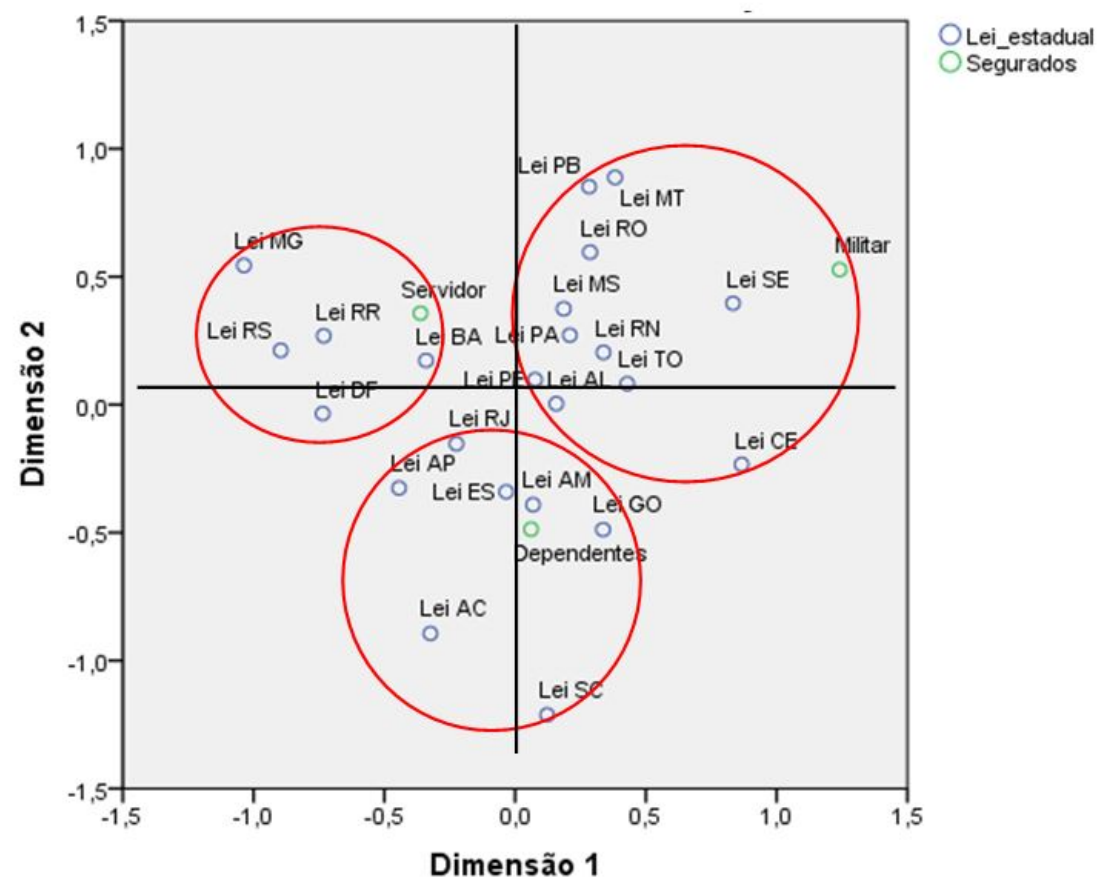

Figura 1 - Mapa Perceptual entre Leis Estaduais e Segurados

Da análise do mapa perceptual, considerando os resíduos padronizados evidenciados em linha na Tabela 4, ou seja, para cada lei estadual, é possível identificar as associações entre as categorias, conforme a seguir:

a) Servidor - cinco leis estaduais: Distrito Federal, Bahia, Minas Gerais, Rio Grande do Sul e Roraima;

b) Militar - onze leis estaduais: Tocantins, Mato Grosso do Sul, Mato Grosso, Rio Grande do Norte, Sergipe, Paraíba, Pernambuco, Alagoas, Ceará, Rondônia e Pará;

c) Dependentes - sete leis estaduais: Goiás, Rio de Janeiro, Espírito Santo, Santa Catarina, Acre, Amazonas e Amapá.

Assim, 47,83\% das leis estaduais guardam similaridade na categoria "militar", 30,43\% na categoria "dependentes" e $21,74 \%$ na categoria "dependentes". Tal fato demonstra que, no que tange à variável "segurados" e suas respectivas categorias, não há um alinhamento preponderante que caracterize a maioria das leis estaduais. Há, pois, uma razoável diversificação para a presente variável.

Uma vez que as leis mais antigas da presente amostra foram as dos estados de Amapá, Ceará e Roraima, instituídas em 1999, conforme consta no Quadro 1, os resultados da ANACOR indicam que 50\% dos demais estados (10 de 20) elaborou suas leis de forma similar à lei do estado do Ceará, no que se refere à categoria "militar". Outros seis estados seguiram a lei do estado do Amapá quanto à categoria "dependentes", e quatro estados se alinharam com a lei do estado de Roraima.

\section{Benefícios}

Quanto à relação entre as leis estaduais e os benefícios do RPPS estadual, a análise foi realizada com base em 2.484 observações. As frequências apresentadas na Tabela de Correspondência (Tabela 5) demonstram que a categoria "aposentadoria" foi a que possuiu mais ocorrências na legislação estadual: 1.297 aparições, sendo 123 registros na lei do estado de Goiás. Em seguida, a categoria com maior frequência foi a "pensões" (688). A lei do estado de Goiás também foi a que apresentou mais incidências nessa categoria: 75 registros. 
Tabela 5 - Tabela de Correspondência (lei estadual e benefícios)

\begin{tabular}{|c|c|c|c|c|c|c|c|}
\hline & Benefícios & & & & & & \\
\hline estadual & Aposentadoria & Pensão & Auxílio-doença & Salário-maternidade & Salário-família & Auxílio-reclusão & $\begin{array}{l}\text { Margem } \\
\text { ativa }\end{array}$ \\
\hline Lei TO & 67 & 23 & 0 & 0 & 1 & 0 & 91 \\
\hline Lei GO & 123 & 75 & 18 & 13 & 10 & 11 & 250 \\
\hline Lei MS & 76 & 29 & 16 & 0 & 15 & 1 & 137 \\
\hline Lei MT & 5 & 2 & 0 & 0 & 0 & 0 & 7 \\
\hline Lei DF & 82 & 42 & 1 & 1 & 16 & 9 & 151 \\
\hline Lei RN & 65 & 29 & 14 & 9 & 11 & 14 & 142 \\
\hline Lei SE & 84 & 32 & 17 & 14 & 17 & 14 & 178 \\
\hline Lei PB & 10 & 2 & 0 & 0 & 1 & 1 & 14 \\
\hline Lei PE & 58 & 22 & 0 & 0 & 2 & 9 & 91 \\
\hline Lei $\mathrm{AL}$ & 54 & 41 & 9 & 4 & 5 & 9 & 122 \\
\hline Lei BA & 70 & 32 & 1 & 1 & 6 & 10 & 120 \\
\hline Lei CE & 11 & 38 & 0 & 0 & 1 & 0 & 50 \\
\hline Lei RJ & 31 & 35 & 0 & 0 & 2 & 13 & 81 \\
\hline Lei ES & 39 & 23 & 0 & 0 & 1 & 10 & 73 \\
\hline Lei MG & 52 & 26 & 0 & 0 & 0 & 6 & 84 \\
\hline Lei RS & 6 & 1 & 1 & 1 & 0 & 1 & 10 \\
\hline Lei SC & 75 & 44 & 0 & 0 & 1 & 10 & 130 \\
\hline Lei RO & 53 & 21 & 9 & 0 & 1 & 9 & 93 \\
\hline Lei RR & 30 & 16 & 0 & 4 & 5 & 8 & 63 \\
\hline Lei PA & 80 & 36 & 0 & 1 & 8 & 0 & 125 \\
\hline Lei AC & 69 & 36 & 13 & 11 & 10 & 11 & 150 \\
\hline Lei AM & 66 & 37 & 10 & 5 & 1 & 4 & 123 \\
\hline Lei AP & 91 & 46 & 16 & 18 & 17 & 11 & 199 \\
\hline $\begin{array}{l}\text { Margem } \\
\text { ativa }\end{array}$ & 1.297 & 688 & 125 & 82 & 131 & 161 & 2.484 \\
\hline
\end{tabular}

A ANACOR explica 16,2\% da variância dos dados (0,162). A primeira dimensão respondeu por 47,6\% $(0,077)$ da variabilidade total dos dados, enquanto a segunda dimensão, 19,7\% (0,032), a terceira, 15,5\% $(0,025)$, a quarta, $10,2 \%(0,017)$ e a quinta, $7,0 \%(0,011)$. Desta forma, o mapa perceptual bidimensional gerado pela ANACOR representa $67,3 \%$ da inércia total.

Em termos da variável "lei estadual", a categoria dominante foi a lei do estado de Sergipe, que contribuiu com 0,159 da inércia da primeira dimensão. Na segunda dimensão, a categoria referente à lei do estado do Ceará foi a mais relevante, respondendo por 0,314 de sua inércia. Quanto à variável "benefícios”, a categoria dominante na primeira dimensão foi “auxílio-doença”, responsável por 0,378 da inércia, enquanto a categoria “pensão" respondeu por 0,394 da inércia da segunda dimensão. 
Tabela 6 - Resíduos Padronizados (lei estadual e benefícios)

\begin{tabular}{|c|c|c|c|c|c|c|}
\hline \multirow{2}{*}{$\begin{array}{l}\text { Lei } \\
\text { estadual }\end{array}$} & \multicolumn{6}{|l|}{ Benefícios } \\
\hline & Aposentadoria & Pensão & Auxílio-doença & Salário-maternidade & Salário-família & Auxílio-reclusão \\
\hline Lei TO & 2,827 & $-0,439$ & $-2,140$ & $-1,733$ & $-1,734$ & $-2,429$ \\
\hline Lei GO & $-0,660$ & 0,692 & 1,528 & 1,652 & $-0,877$ & $-1,293$ \\
\hline Lei MS & 0,528 & $-1,452$ & 3,468 & $-2,127$ & 2,893 & $-2,644$ \\
\hline Lei MT & 0,704 & 0,044 & $-0,594$ & $-0,481$ & $-0,608$ & $-0,674$ \\
\hline Lei DF & 0,355 & 0,027 & $-2,394$ & $-1,785$ & 2,848 & $-0,252$ \\
\hline Lei RN & $-1,062$ & $-1,647$ & 2,564 & 1,992 & 1,283 & 1,581 \\
\hline Lei SE & $-0,927$ & $-2,464$ & 2,687 & 3,351 & 2,485 & 0,725 \\
\hline Lei PB & 0,995 & $-0,954$ & $-0,839$ & $-0,680$ & 0,305 & 0,097 \\
\hline Lei PE & 1,521 & $-0,638$ & $-2,140$ & $-1,733$ & $-1,278$ & 1,277 \\
\hline Lei AL & $-1,216$ & 1,240 & 1,155 & $-0,014$ & $-0,565$ & 0,389 \\
\hline Lei BA & 0,928 & $-0,215$ & $-2,050$ & $-1,488$ & $-0,131$ & 0,797 \\
\hline Lei CE & $-2,957$ & 6,490 & $-1,586$ & $-1,285$ & $-1,008$ & $-1,800$ \\
\hline Lei RJ & $-1,737$ & 2,653 & $-2,019$ & $-1,635$ & $-1,099$ & 3,382 \\
\hline Lei ES & 0,143 & 0,618 & $-1,917$ & $-1,552$ & $-1,452$ & 2,422 \\
\hline Lei MG & 1,229 & 0,567 & $-2,056$ & $-1,665$ & $-2,105$ & 0,238 \\
\hline Lei RS & 0,341 & $-1,063$ & 0,700 & 1,166 & $-0,726$ & 0,437 \\
\hline Lei SC & 0,864 & 1,332 & $-2,558$ & $-2,072$ & $-2,236$ & 0,542 \\
\hline Lei RO & 0,637 & $-0,938$ & 1,997 & $-1,752$ & $-1,763$ & 1,211 \\
\hline Lei RR & $-0,505$ & $-0,347$ & $-1,781$ & 1,332 & 0,920 & 1,938 \\
\hline Lei PA & 1,824 & 0,234 & $-2,508$ & $-1,539$ & 0,548 & $-2,846$ \\
\hline Lei $\mathrm{AC}$ & $-1,053$ & $-0,860$ & 1,984 & 2,718 & 0,743 & 0,410 \\
\hline Lei AM & 0,222 & 0,502 & 1,532 & 0,466 & $-2,154$ & $-1,407$ \\
\hline Lei AP & $-1,266$ & $-1,228$ & 1,892 & 4,460 & 2,008 & $-0,529$ \\
\hline
\end{tabular}

Analisando-se os valores da Tabela 6, que apresenta os resíduos padronizados das duas variáveis em questão, é possível realizar a seguinte caracterização, considerando os valores positivos das colunas, que evidenciam maior associação entre as variáveis:

a) Aposentadoria - catorze leis dos estados em ordem decrescente de importância: Tocantins, Pará, Pernambuco, Minas Gerais, Paraíba, Bahia, Santa Catarina, Mato Grosso, Rondônia, Mato Grosso do Sul, Distrito Federal, Rio Grande do Sul, Amazonas e Espírito Santo;

b) Pensão - onze leis dos estados em ordem decrescente de importância: Ceará, Rio de Janeiro, Santa Catarina, Alagoas, Goiás, Espírito Santo, Minas Gerais, Amazonas, Pará, Mato Grosso e Distrito Federal;

c) Auxílio-doença - dez leis dos estados em ordem decrescente de importância: Mato Grosso do Sul, Sergipe, Rio Grande do Norte, Roraima, Acre, Amapá, Amazonas, Goiás, Alagoas e Rio Grande do Sul;

d) Salário-maternidade - oito leis dos estados em ordem decrescente de importância: Amapá, Sergipe, Acre, Rio Grande do Norte, Goiás, Roraima, Rio Grande do Sul e Amazonas;

e) Salário-família - nove leis dos estados em ordem decrescente de importância: Mato Grosso do Sul, Distrito Federal, Sergipe, Amapá, Rio Grande do Norte, Roraima, Acre, Pará e Paraíba; e

f) Auxílio-reclusão - catorze leis dos estados em ordem decrescente de importância: Rio de Janeiro, Espírito Santo, Roraima, Rio Grande do Norte, Pernambuco, Rondônia, Bahia, Sergipe, Santa Catarina, Rio Grande do Sul, Acre, Alagoas, Minas Gerais e Paraíba.

Essa caracterização demonstra que não há uma categoria preponderante entre as seis possíveis. Nota-se que há uma distribuição razoavelmente equilibrada entre as categorias das variáveis em questão. É de se esperar que essas associações estejam próximas no mapa perceptual, uma vez que indicam a similaridade existente entre as respectivas leis e cada uma das categorias da variável "benefícios". 


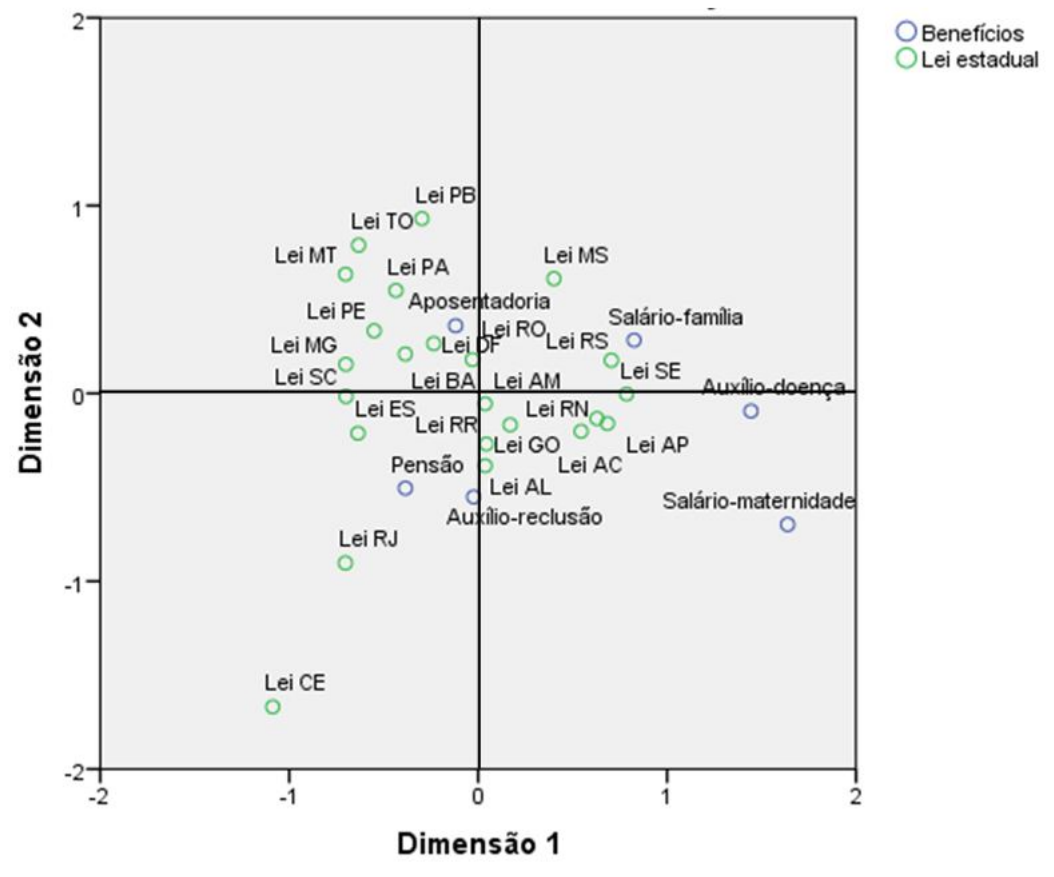

Figura 2 - Mapa Perceptual entre Leis Estaduais e Benefícios

A análise feita por um mapa perceptual não nos permite identificar, de forma simplificada e interpretável, associações entre as categorias das variáveis. Percebe-se que não ocorrem distâncias relativamente grandes entre as categorias das variáveis em análise de forma a gerar associações específicas. Assim, seria possível concluir que as leis estaduais abordam as categorias da variável "benefícios" de maneira quase similar.

Figura

\section{Financiamento}

O último par de variáveis analisadas refere-se às leis estaduais e à forma de financiamento do RPPS desenvolvida a partir de um total de 1.864 observações. As frequências apresentadas na Tabela de Correspondência (Tabela 7) demonstram que a categoria "contribuição" foi a que possui mais ocorrências, 1.443, seguida pela categoria "fundo", com 360 registros. A lei do estado de Goiás foi a que apresentou mais incidência na categoria "contribuição": 143 registros. A lei do estado de Pernambuco evidenciou 86 aparições na categoria "fundo". 
Tabela 7 - Tabela de Correspondência (lei estadual e financiamento)

\begin{tabular}{lllll}
\hline $\begin{array}{l}\text { Lei } \\
\text { estadual }\end{array}$ & \multicolumn{3}{l}{ Financiamento } & \\
\hline Lei TO & 69 & 20 & 3 & $\begin{array}{l}\text { Margem } \\
\text { ativa }\end{array}$ \\
Lei GO & 143 & 4 & 5 & 92 \\
Lei MS & 80 & 20 & 1 & 152 \\
Lei MT & 11 & 0 & 0 & 101 \\
Lei DF & 84 & 20 & 3 & 11 \\
Lei RN & 72 & 31 & 6 & 107 \\
Lei SE & 95 & 4 & 1 & 109 \\
Lei PB & 9 & 0 & 2 & 100 \\
Lei PE & 78 & 86 & 4 & 11 \\
Lei AL & 72 & 49 & 9 & 168 \\
Lei BA & 64 & 0 & 0 & 130 \\
Lei CE & 28 & 1 & 0 & 64 \\
Lei RJ & 26 & 3 & 0 & 29 \\
Lei ES & 54 & 17 & 2 & 29 \\
Lei MG & 86 & 14 & 3 & 73 \\
Lei RS & 11 & 19 & 1 & 103 \\
Lei SC & 92 & 18 & 4 & 31 \\
Lei RO & 30 & 3 & 1 & 114 \\
Lei RR & 33 & 4 & 0 & 34 \\
Lei PA & 66 & 13 & 3 & 37 \\
Lei AC & 71 & 5 & 2 & 82 \\
Lei AM & 55 & 28 & 2 & 78 \\
Lei AP & 114 & 1 & 9 & 85 \\
Margem & 1.443 & 360 & 61 & 124 \\
ativa & 1.43 & & & 1.864 \\
\hline
\end{tabular}

Os resultados da ANACOR explicam 18,1\% da inércia total $(0,181)$, sendo $90,9 \%$ na primeira dimensão $(0,164)$ e $9,1 \%$ na segunda dimensão $(0,017)$.

Para a variável "lei estadual", a categoria dominante diz respeito à lei do estado de Pernambuco, contribuindo com 0,354 da inércia da primeira dimensão. Na segunda dimensão, a categoria dominante foi a lei do estado da Paraíba, com 0,259 da inércia da dimensão. No que se refere à variável "financiamento", a categoria dominante na primeira dimensão foi a de "fundo", responsável por 0,794 da inércia, enquanto a categoria "compensação" respondeu por 0,966 da segunda dimensão. Tem-se, assim, que, muito embora seja mais frequente, a categoria "contribuição" não é dominante na primeira dimensão, mas sim "fundo". Outro aspecto que merece comentário é o quão dominante é a categoria "compensação" na segunda dimensão. Entretanto, tal dimensão responde por apenas 9,1\% da inércia total. Ou seja, as associações são, basicamente, explicadas na primeira dimensão. 
Tabela 8 - Resíduos Padronizados (lei estadual e financiamento)

\begin{tabular}{llll}
\hline Lei & \multicolumn{3}{l}{ Financiamento } \\
\cline { 2 - 4 } estadual & Contribuição & Fundo & Compensação \\
\hline Lei TO & $-0,263$ & 0,529 & $-0,006$ \\
Lei GO & 2,335 & $-4,680$ & 0,012 \\
Lei MS & 0,205 & 0,112 & $-1,268$ \\
Lei MT & 0,851 & $-1,458$ & $-0,600$ \\
Lei DF & 0,128 & $-0,146$ & $-0,268$ \\
Lei RN & $-1,348$ & 2,168 & 1,288 \\
Lei SE & 1,999 & $-3,485$ & $-1,256$ \\
Lei PB & 0,166 & $-1,458$ & 2,733 \\
Lei PE & $-4,565$ & 9,402 & $-0,639$ \\
Lei AL & $-2,855$ & 4,768 & 2,301 \\
Lei BA & 2,054 & $-3,516$ & $-1,447$ \\
Lei CE & 1,171 & $-1,944$ & $-0,974$ \\
Lei RJ & 0,749 & $-1,099$ & $-0,974$ \\
Lei ES & $-0,334$ & 0,773 & $-0,252$ \\
Lei MG & 0,701 & $-1,321$ & $-0,202$ \\
Lei RS & $-2,653$ & 5,318 & $-0,014$ \\
Lei SC & 0,399 & $-0,856$ & 0,139 \\
Lei RO & 0,717 & $-1,392$ & $-0,107$ \\
Lei RR & 0,814 & $-1,177$ & $-1,100$ \\
Lei PA & 0,316 & $-0,713$ & 0,193 \\
Lei AC & 1,366 & $-2,593$ & $-0,346$ \\
Lei AM & $-1,332$ & 2,859 & $-0,469$ \\
Lei AP & 1,838 & $-4,689$ & 2,453 \\
\hline & & & \\
\hline
\end{tabular}

Os valores apresentados na Tabela 8, referente aos resíduos padronizados das variáveis em questão, viabilizam a seguinte caracterização, a partir dos valores positivos das colunas, que evidenciam maior associação entre as variáveis:

a) Contribuição - catorze leis dos estados em ordem decrescente de importância: Tocantins, Pará, Pernambuco, Minas Gerais, Paraíba, Bahia, Santa Catarina, Mato Grosso, Rondônia, Mato Grosso do Sul, Distrito Federal, Rio Grande do Sul, Amazonas e Espírito Santo;

b) Fundo - onze leis dos estados em ordem decrescente de importância: Ceará, Rio de Janeiro, Santa Catarina, Alagoas, Goiás, Espírito Santo, Minas Gerais, Amazonas, Pará, Mato Grosso e Distrito Federal;

c) Compensação - dez leis dos estados em ordem decrescente de importância: Mato Grosso do Sul, Sergipe, Rio Grande do Norte, Rondônia, Acre, Amapá, Amazonas, Goiás, Alagoas e Rio Grande do Sul.

Essa caracterização demonstra que não há uma categoria preponderante entre as três possíveis. Há uma razoável distribuição entre as mesmas. É de se esperar que essas associações estejam próximas no mapa perceptual, uma vez que indicam a similaridade existente entre as respectivas leis e cada uma das categorias da variável "financiamento". A representação gráfica conjunta dessas variáveis é apresentada na Figura 3. 


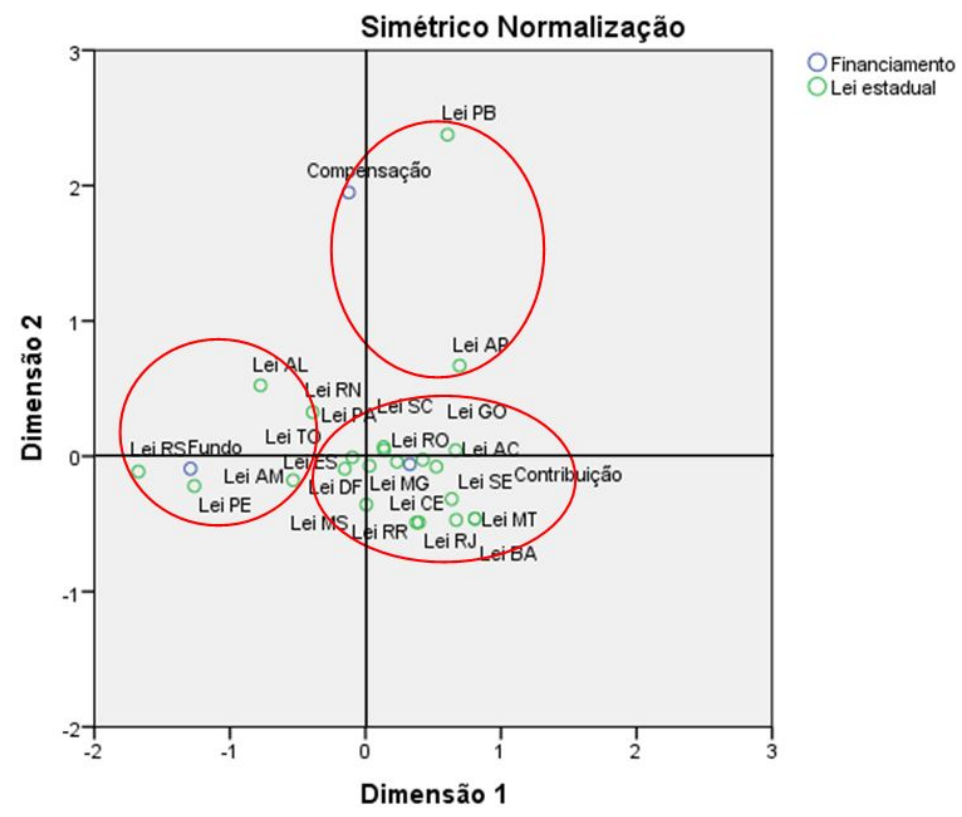

Figura 3 - Mapa Perceptual entre Leis Estaduais e Formas de Financiamento

Da análise do mapa perceptual, considerando os resíduos padronizados evidenciados em linha na Tabela 8, ou seja, para cada lei estadual, é possível identificar as associações entre as categorias, conforme a seguir:

a) Contribuição - catorze leis estaduais: Goiás, Mato Grosso do Sul, Mato Grosso, Distrito Federal, Sergipe, Bahia, Ceará, Rio de Janeiro, Minas Gerais, Santa Catarina, Rondônia, Roraima, Pará e Acre;

b) Fundo - sete leis estaduais: Tocantins, Rio Grande do Norte, Pernambuco, Alagoas, Espírito Santo, Rio Grande do Sul e Amazonas;

c) Compensação - duas leis estaduais: Paraíba e Amapá.

Desta forma, 60,87\% das leis estaduais guardam similaridade na categoria "contribuição", 30,43\% na categoria "fundo" e 8,70\% na categoria "compensação". Tais percentuais demonstram que a maioria das leis estaduais são similares no que diz respeito à atenção dispensada para a contribuição ao RPPS. Tem-se, ainda, que a modalidade de financiamento conhecida como "compensação" foi pouco abordada na legislação estadual que criou os RPPS.

Considerando que as leis mais antigas desta amostra são as leis dos estados do Amapá, Ceará e Roraima, instituídas em 1999, conforme já visualizado no Quadro 1, os resultados da ANACOR indicam que 60\% dos demais estados (12 de 20) elaborou suas leis de forma similar às leis do estado do Ceará e de Roraima, no que se refere à categoria "contribuição". Apenas o estado da PB seguiu a caracterização da lei de AP. Além disso, os resultados sugerem que a lei do estado de PE, instituída em 2000, serviu de referência, na categoria "fundo", para seis estados.

\section{CONSIDERAÇÕES FINAIS}

O presente estudo exploratório se propôs a analisar a legislação previdenciária dos estados brasileiros e do Distrito Federal que instituiu seu Regime Próprio de Previdência Social (RPPS), visando identificar práticas de isomorfismo institucional, que podem contribuir para o entendimento de parte dos resultados previdenciários deficitários apresentados.

Após o levantamento da legislação estadual, foi realizada uma análise de conteúdo das leis mantidas na amostra, com vistas a identificar a frequência dos elementos correspondentes às variáveis qualitativas 
e suas respectivas categorias empregadas neste estudo: Variável "segurados", com as categorias "servidor", "militar" e "dependentes"; variável "benefícios", com as categorias "aposentadoria”, "pensão", "auxíliodoença", "salário-maternidade", "salário-família" e "auxílio-reclusão"; e variável "financiamento", com as categorias "contribuição", "fundo" e "compensação".

Em seguida, foram analisadas as associações entre as categorias das variáveis com o apoio da técnica de interdependência Análise de Correspondência, a partir dos mapas perceptuais bidimensionais gerados, bem como das medidas de similaridades (resíduos padronizados) das variáveis.

Foi possível constatar que $47,83 \%$ das leis estaduais guardam similaridade na categoria "militar", 30,43\% na categoria "dependentes" e 21,74\% na categoria "dependentes". Além disso, tomando como referência os primeiros estados a instituírem leis criando o RPPS estadual (CE, AP e RR, em 1999), 10 de 20 estados (50\%) elaboraram suas leis de forma similar à lei do estado do Ceará, no que se refere à categoria "militar". Outros seis estados seguiram a lei do estado do Amapá quanto à categoria "dependentes", e quatro estados alinharamse com a lei do estado de Roraima.

A análise mapa perceptual não nos permitiu identificar, de forma simplificada e interpretável, associações entre as categorias das variáveis "lei estadual" e "benefícios". Não foram identificadas distâncias relativamente grandes entre as categorias dessas variáveis de forma a gerar associações específicas. Desta maneira, seria possível concluir que as leis estaduais abordam as categorias da variável "benefícios" de uma maneira quase similar.

Por fim, verificou-se que $60,87 \%$ das leis estaduais guardam similaridade na categoria "contribuição", 30,43\% na categoria "fundo" e 8,70\% na categoria "compensação". A partir das leis estaduais utilizadas como referência para análise de práticas de isomorfismo, notou-se que 12 de 20 estados (60\%) elaboraram suas leis de forma similar às leis do estado do $\mathrm{CE}$ e de RR, no que se refere à categoria "contribuição". Apenas o estado da Paraíba seguiu a caracterização da lei de Amapá. Além disso, os resultados sugerem que a lei do estado de Pernambuco, instituída em 2000, foi utilizada como referência, na categoria “fundo", para seis estados.

Apesar das limitações deste estudo, como a não cobertura total dos estados brasileiros, os resultados viabilizaram a identificação de evidências de isomorfismo em todas as variáveis analisadas, com níveis distintos de relacionamentos entre as categorias das variáveis, sendo, entretanto, mais relevante para a variável "benefícios", cujo mapa perceptual não foi capaz de fornecer associações específicas. Tais resultados podem contribuir para explicar parte dos déficits previdenciários incorridos pelos estados brasileiros e pelo Distrito Federal.

Cabe ressaltar ainda que, muito embora não tenha sido escopo de análise pormenorizada neste estudo, a identificação de práticas de isomorfismo, haja vista os resultados previdenciários evidenciados pelos estados brasileiros, contribuiu para o discurso de não garantia de eficiência a partir de sua adoção, como destacaram DiMaggio e Powell (1983) e Pimentel, Chalerge e Porto (2015).

Não obstante os achados de Lima et al. (2015), referentes à adoção do isomorfismo institucional nas práticas de governança corporativa adotadas e divulgadas pelos fundos de pensão brasileiros, a sugestão de Paula et al. (2018), por exemplo, de emprego do isomorfismo como ferramenta para melhoria da adequação da estrutura legal aos mecanismos de governança e accountability pode lograr ou não êxito, em função da existência de outras variáveis que devem ser consideradas.

Assim, considerando a relevância do tema, em todos os níveis de governo, e a carência de debates no ambiente acadêmico nacional, trabalhos futuros poderiam dar continuidade à análise de práticas de isomorfismo na legislação previdenciária dos estados brasileiros e do Distrito Federal, considerando as demais espécies legislativas não abordadas neste estudo, que disciplinam o respectivo RPPS, o que poderia incrementar o entendimento dos déficits da previdência. 


\section{REFERÊNCIAS}

Boxenbaum, E., \& Jonsson, S. (2017). Isomorphism, Diffusion and Decoupling: Concept Evolution and Theoretical Challenges. In: Greenwood, R., Oliver, C., Lawrence, T. B., \& Meyer, R. E. The SAGE Handbook of Organizational Institutionalism. $2^{\text {nd }}$ Edition. The SAGE Publishing.

Bowen, C. C., \& Bowen, W. M. (2008). Content Analysis. In: Miller, G. J.; \& Yang, K. Handbook of Research Methods in Public Administration. $2^{\text {nd }}$ Edition. Taylor \& Francis Group, LLC.

Constituição da República Federativa do Brasil. (1988). Brasília, DF.

Braun, J. J. D. (2014). Accountability Previdenciária. In: Mognon, A. (Org.). Regimes Próprios: Aspectos Relevantes. $9^{\circ}$ volume. São Bernardo do Campo: SP.

Campbell, D. (2017). Content Analysis. In: Hoque, Z., Parker, L. D., Covaleski, M. A., \& Haynes, K. The Routledge Companion to Qualitative Accounting Research Methods. Cap. 21, 354-371.

Dias, J. M., Filho, \& Machado, L. H. B. (2008). Abordagens da pesquisa em contabilidade. In: Iudícibus, S., \& Lopes, A. B. (Org.). Teoria Avançada da Contabilidade. São Paulo: Atlas.

DiMaggio, P. T., \& Powell, W. W. (1983). The Iron Cage Revisited: Institutional Isomorphism and Collective Rationality in Organizational Fields. American Sociological Review, 48(2), 147-160.

Fávero, L. P., Belfiore, P., Silva, F. L., \& Chan, B. L. (2009). Análise de Dados: Modelagem Multivariada para Tomada de Decisões. Rio de Janeiro: Elsevier.

Ibrahim, F. Z. (2011). A previdência social no estado contemporâneo: fundamentos, financiamento e regulação. Niterói, RJ: Impetus.

Krippendorff, K. (2004). Content Analysis: An Introduction to its Methodology. $2^{\text {nd }}$ Edition. Sage Publications.

Lei n. 9.717, de 27 de novembro de 1998. (1998). Dispõe sobre regras gerais para a organização e o funcionamento dos regimes próprios de previdência social dos servidores públicos da União, dos Estados, do Distrito Federal e dos Municípios, dos militares dos Estados e do Distrito Federal e dá outras providências. Brasília, DF.

Lima, L. C., Oliveira, M. C., Ponte, V. M. R., \& Rebouças, S. M. D. P. (2015). Práticas de Governança Corporativa Adotadas e Divulgadas pelos Fundos de Pensão Brasileiros. Revista Contemporânea de Contabilidade, 12(27), 3-26.

Machado-da-Silva, C. L., \& Fonseca, V. S. (1993). Homogeneização e diversidade organizacional: uma visão integrativa. Anais do Encontro da Associação Nacional de Pós-Graduação e Pesquisa em Administração, Salvador, BA, Brasil, 23.

Meyer, J. W., \& Rowan, B. (1977). Institutionalized Organizations: Formal Structure as Myth and Ceremony. American Journal of Sociology, 83(2), 340-363.

Ministério da Economia (ME). (2019). Exposição de Motivos Interministerial n. 29, de 20 de fevereiro de 2019. Brasília, DF.

Paula, B. T., Faria, E. R., França, V. M., \& Tavares, B. (2018). Accountability em Regimes Próprios de Previdência Social (RPPS) nas Diferentes Mesorregióes de Minas Gerais. Anais do Encontro Nacional dos Cursos de Graduação em Administração, São Paulo, SP, Brasil, 29.

Pimentel, V. M., Chalerge, O., \& Porto, M. I. (2015). A Difusão da Política de Privatização da Previdência na América Latina. Revista Brasileira de Previdência: Atuária, Contabilidade e Direito Previdenciário, 4(1). 1-23.

Santos, C. H. M., Almeida, V. L., Caldas, L. F., Sá, J. H. B., Machado, U. E. N., Martins, F. S., \& Brito, A. J. S. (2017). A Dinâmica do Déficit dos Regimes Próprios de Previdência dos Estados Brasileiros nos Anos 2006-2015. Carta de Conjuntura n. 34, $1^{\circ}$ trimestre. Brasília: IPEA.

Secretaria do Tesouro Nacional (STN). (2018). Boletim de Finanças dos Entes Subnacionais.

Tafner, P. (2007). Seguridade e Previdência: Conceitos Fundamentais. In: Tafner, P., \& Giambiagi, F. (Org.). Previdência no Brasil: debates, dilemas e escolhas. Rio de Janeiro: IPEA. 
Anderson Chaves da Silva, et al. Regimes Próprios de Previdência Social: Uma Análise à Luz do Isom...

World Bank. (2017). Summary Note on Pension Reform in Brazil: Why is it Needed and What Will be its Impact? World Bank, Washington, DC. Recuperado em 20 outubro, 2017, de https://openknowledge.worldbank.org/ handle/10986/26388.

CC BY-NC-ND 